\title{
The miR-200 family: multiple effects on gliomas
}

This article was published in the following Dove Press journal:

Cancer Management and Research

\section{Lilei Peng' \\ Jie $\mathrm{Fu}^{2}$ \\ Yang Ming'}

'Department of Neurosurgery, The Affiliated Hospital of Southwest

Medical University, Luzhou 646000,

People's Republic of China;

${ }^{2}$ Department of Neurology, The

Affiliated Hospital of Southwest

Medical University, Luzhou 646000 ,

People's Republic of China
Correspondence: Yang Ming

Department of Neurosurgery, The Affiliated Hospital of Southwest Medical

University, Taiping Street, Jiangyang

District, Luzhou 646000, People's

Republic of China

Email II388I360@qq.com
Abstract: Gliomas are the most common type of primary brain tumors. MicroRNAs (miRNAs) are small noncoding RNAs that can epigenetically regulate target gene expression. The microRNA 200 family includes miR-200a, 200b, 200c, 141 and 429. Numerous studies have indicated that members of the miR-200 family play an important role in glioma development and metastasis. In this review, we summarize the data from various studies and highlight the effects of miR-200 on glioma metastasis, therapeutic response and prognosis.

Keywords: glioma, miR-200 family, metastasis, chemoresistance, radioresistance

\section{Introduction}

Gliomas are the most common type of primary brain tumors, accounting for almost $30 \%$ of central nervous system tumors and $80 \%$ of all malignant brain tumors. ${ }^{1,2}$ Based on the World Health Organization (WHO) classification, gliomas can be divided into four grades - WHO I, II, III and IV. ${ }^{3}$ Glioblastoma (GBM; WHO grade IV) is the most common and aggressive primary brain tumor in adults, accounting for $\sim 46 \%$ of primary malignant brain tumors. ${ }^{4}$ Gliomas are characterized by their rapid growth and high degree of infiltration. Despite the difficulty in surgically removing gliomas, ${ }^{5}$ the current primary treatments include surgical resection, radiotherapy and chemotherapy. Unfortunately, despite the remarkable development in surgery and adjuvant therapy, the median survival rate for patients with gliomas has not considerably improved over the past few decades. Furthermore, clinical outcomes remain poor due to the adverse events that accompany these treatments and the increasing resistance to radiotherapy and chemotherapy. ${ }^{6-8}$ The underlying mechanisms of glioma pathogenesis are still largely unknown. Thus, improving our understanding of glioma molecular pathogenesis is necessary to develop more efficacious and precise treatment schemes.

MicroRNAs (miRNAs) are small noncoding RNAs that are 17-24 nucleotides in length. miRNAs regulate target gene expression through inhibiting translation or degrading target mRNAs. ${ }^{9}$ It has been reported that miRNAs regulate cell growth associated with the development and metastasis of cancers. ${ }^{10}$ Some miRNAs have been specifically implicated in glioma pathogenesis. For example, recent reviews have indicated that circulating miRNAs could be potential glioma biomarkers and reported that miRNAs are associated with drug resistance, which may have direct therapeutic implications. ${ }^{9,11,12}$

The miRNA-200 family consists of miR-200a, 200b, 200c, 141 and 429. All these miRNAs are derived from two different gene clusters. miR-200a, miR-200b and miR-429 are derived from chromosome 1p33.36, and miR-200c and miR-141 
are derived from chromosome 12p13.3 (Table 1). ${ }^{13}$ These miRNAs are highly homologous, with only one nucleotide difference in their seed sequences (Table 1). ${ }^{13}$ Increasing evidence demonstrates that the microRNA-200 family is closely associated with glioma initiation, progression and metastasis. ${ }^{14,15}$ The goal of this review is to update the research field on the multiple roles of the miR-200 family in gliomas.

\section{miR-200 expression in gliomas}

Studies that have identified miRNAs that are aberrantly expressed in gliomas have provided important information regarding the roles of miRNAs in tumor biology. Studies that focused on the miRNA-200 family have offered new insight into glioma development and metastasis. Interestingly, while these studies have utilized different detection platforms and samples to identify differentially expressed miRNAs (Table 2), the majority found that miR-200a, 200b, 200c, 141 and 429 are downregulated in glioma tissues. ${ }^{15-22}$ More interestingly, miR-200a was consistently lower in grade IV (GBMs) gliomas compared to low-grade II and III (LGs) gliomas, suggesting that miR-200a is responsible for glioma histological grading. ${ }^{17}$ However, some members of the miR-200 family were upregulated in gliomas. For example, one study showed that miR-429 was upregulated in glioma compared to non-neoplastic brain tissues. ${ }^{23}$ Another study demonstrated that miR-141-3p was upregulated in high-grade gliomas (grades III and IV) compared to that of non-cancerous brain tissues or even LG gliomas (grades I and II). ${ }^{24}$ Intriguingly, although one study showed that miR-200b was upregulated in glioma compared to normal brain tissues, inhibiting miR$200 \mathrm{~b}$ expression enhanced pathological grading of glioma; therefore, miR-200b was still thought to be a tumor suppressor gene. ${ }^{25}$ Of note, the reduced expression of miRNAs in the miR-200 family in gliomas was associated with epigenetic regulation. One study reported that DNA methylation and histone modifications repressed miR-200a, 200b and 429 expression, which promoted glioblastoma progression. ${ }^{26}$
The variation in miRNA expression data from these studies might reflect a context-dependent expression pattern that relies on histological type or glioma grade. Indeed, it was reported that dysregulation of miRNAs might be associated with tumor stage, grade and progression status. ${ }^{27}$ Therefore, the underlying mechanism of miRNA control of glioma warrants additional research.

\section{miR-200 and metastasis of gliomas}

Metastasis involves multiple steps that promote tumor cells to migrate from the primary tumor site and colonize in distant organs or tissues. ${ }^{28}$ Interestingly, extracranial metastasis is rare in malignant gliomas, ${ }^{29}$ which has been reported in only $\sim 0.5 \%$ of patients. ${ }^{30}$ The low incidence of extracranial metastasis could be attributed to some intrinsic biological obstacles, such as lack of the lymphatic system, which is crucial for systemic dissemination, or the presence of dense dura around cerebral veins, which inhibits tumor cell migration. ${ }^{29}$

One study indicated that miR-200a inhibits glioma cell growth, migration and invasion by targeting single-minded homolog 2-short form (SIM2-s). ${ }^{16}$ Similarly, many studies have demonstrated that miR-200b inhibits glioma cell proliferation and invasion. More specifically, miR-200b can target different genes, including cAMP responsive element-binding protein 1 (CREB1), zinc finger E-box binding homeobox 2 (ZEB2), prominin 1 (PROM1), extracellular signal-regulated kinase 5 (ERK5), CD133 ${ }^{10,19,31-33}$ and lactate dehydrogenase A (LDHA), which is associated with glioma cell proliferation and invasion. Therefore, targeting LDHA by miR-200b is regarded as a promising therapeutic strategy in glioma. ${ }^{34}$ Moreover, miR-200b was reported to be involved in bloodtumor barrier (BTB) permeability. For example, miR-200b overexpression was associated with reduced expression of RhoA and ROCKII and subsequently contributed to a decrease in BTB permeability. ${ }^{35}$ Therefore, downregulation of miR-200b may initiate a signaling cascade that increases BTB permeability and facilitates glioma cell invasion.

Table I The miR-200 family and their seed sequences

\begin{tabular}{lll}
\hline miR-200 & Chromosome Location & Seed sequence of mature miRNAs \\
\hline miR-200a & chromosome Ip33.36 & UAACACUGUCUGGUAACGAUGU \\
miR-200b & chromosome Ip33.36 & UAA U ACUGCCUGGUAAUGAUGA \\
miR-200c & chromosome I2pI3.31 & UAA UACUGCCGGGUAAUGAUGGA \\
miR-14I & chromosome I2pI3.3I & UAA C ACUGUCUGGUAAAGAUGG \\
miR-429 & chromosome Ip33.36 & UAA U ACUGUCUGGUAAAACCGU \\
\hline
\end{tabular}

Note: Seed nucleotide differences are highlighted.

Abbreviation: miRNAs, microRNAs. 
Table 2 Literature summary of studies focused on miRNA 200 family expression in gliomas

\begin{tabular}{|c|c|c|c|}
\hline Study & Samples/controls & miR-200 expression & Conclusion \\
\hline Su et al $(2014)^{16}$ & $\begin{array}{l}\text { Samples: human glioma } \\
\text { Controls: normal brain tissue }\end{array}$ & $\begin{array}{l}\text { Decreased expression of miR-200a in } \\
\text { glioma samples compared to normal } \\
\text { brain tissue }\end{array}$ & $\begin{array}{l}\text { miR-200a acted as a tumor suppressor by } \\
\text { targeting the SIM2-s gene in gliomas }\end{array}$ \\
\hline Berthois et al $(2014)^{17}$ & $\begin{array}{l}\text { Samples: } 24 \text { primary GBMs } \\
\text { Controls: } 10 \text { low grade brain tumors } \\
\text { (LGs) }\end{array}$ & $\begin{array}{l}\text { miR200a was downregulated in GBMs } \\
\text { compared to LGs }\end{array}$ & $\begin{array}{l}\text { miR200a was involved in glioma } \\
\text { progression and therapeutic response }\end{array}$ \\
\hline Liu et al $(20 \mid 4)^{18}$ & $\begin{array}{l}\text { Samples: } 73 \text { glioma tissues } \\
\text { Controls: } 30 \text { normal brain tissues }\end{array}$ & $\begin{array}{l}\text { miR-200b was downregulated in } \\
\text { glioma tissues }\end{array}$ & $\begin{array}{l}\text { miR-200b, as a tumor suppressor by } \\
\text { targeting the RAB family, was a potential } \\
\text { biomarker for glioma prognosis }\end{array}$ \\
\hline Li et al $(2016)^{19}$ & $\begin{array}{l}\text { Samples: } 88 \text { cases of glioma specimens } \\
\text { Controls: } 25 \text { normal brain tissues }\end{array}$ & $\begin{array}{l}\text { miR-200b levels were decreased in } \\
\text { primary glioma tissues compared to } \\
\text { normal brain tissues }\end{array}$ & $\begin{array}{l}\text { miR-200b had suppressive effects on } \\
\text { glioma cells via targeting ZEB2 }\end{array}$ \\
\hline Wang et al $(2015)^{25}$ & $\begin{array}{l}\text { Samples: primary gliomas from } 123 \\
\text { patients (including } 38 \text { astrocytoma, } 53 \\
\text { glioblastoma, and } 32 \text { ependymoma) } \\
\text { Controls: normal brain tissues }\end{array}$ & $\begin{array}{l}\text { miR-200b was increased in glioma } \\
\text { tissues compared with normal } \\
\text { brain tissues. A decrease in miR- } \\
\text { 200b expression with increasing } \\
\text { pathological grading of gliomas }\end{array}$ & $\begin{array}{l}\text { miR-200b levels were associated with the } \\
\text { histological grading of gliomas. miR-200b } \\
\text { could become a useful independent } \\
\text { prognostic factor for glioma }\end{array}$ \\
\hline Qin et al $(2017)^{15}$ & $\begin{array}{l}\text { Samples: human glioma samples } \\
\text { (including grade II, grade III, and grade } \\
\text { IV glioma tissues) } \\
\text { Controls: paratumor tissues }\end{array}$ & $\begin{array}{l}\text { miR-200c was reduced in glioma } \\
\text { tissues compared to paratumor } \\
\text { tissues }\end{array}$ & $\begin{array}{l}\text { miR-200c played an important role in } \\
\text { regulating glioma by targeting moesin }\end{array}$ \\
\hline Peng et al $(2016)^{20}$ & $\begin{array}{l}\text { Samples: glioma tissues from } 36 \\
\text { patients with primary glioma } \\
\text { Controls: adjacent normal tissues }\end{array}$ & $\begin{array}{l}\text { miR- } 14 \mid \text { was lower in glioma } \\
\text { compared to adjacent non-cancerous } \\
\text { tissues }\end{array}$ & $\begin{array}{l}\text { miR-I4I acted as a tumor suppressor by } \\
\text { targeting TGF- } \beta 2\end{array}$ \\
\hline Zhou et al $(2017)^{24}$ & $\begin{array}{l}\text { Samples: } 27 \text { human glioma specimens } \\
\text { Controls: } 5 \text { normal brain tissues }\end{array}$ & $\begin{array}{l}\text { miR- } 14 \mid-3 p \text { was increased in glioma } \\
\text { tissues }\end{array}$ & $\begin{array}{l}\text { miR- } 14 \mid-3 p \text { promoted tumor growth by } \\
\text { targeting } \mathrm{P} 53 \text { and increased resistance in } \\
\text { glioma cells to temozolomide }\end{array}$ \\
\hline Chen et al $(2015)^{21}$ & $\begin{array}{l}\text { Samples: } 12 \text { glioma tissues } \\
\text { Controls: adjacent non-tumor tissues }\end{array}$ & $\begin{array}{l}\text { miR- } 429 \text { was lower in glioma tissues } \\
\text { than in adjacent non-neoplastic tissues }\end{array}$ & $\begin{array}{l}\text { miR- } 429 \text { had an important function } \\
\text { in glioma invasion through BMKI } \\
\text { suppression }\end{array}$ \\
\hline Sun et al $(2016)^{23}$ & $\begin{array}{l}\text { Samples: } 92 \text { gliomas (including II } \\
\text { grade I, } 37 \text { grade II, } 24 \text { grade III, and } \\
20 \text { grade IV) } \\
\text { Controls: non-neoplastic brain tissues }\end{array}$ & $\begin{array}{l}\text { miR- } 429 \text { was increased in glioma } \\
\text { tissues compared to non-neoplastic } \\
\text { brain tissues }\end{array}$ & $\begin{array}{l}\text { miR- } 429 \text { was upregulated in glioma } \\
\text { tissues. Patients with high miR- } 429 \text { level } \\
\text { had lower } 5 \text {-year survival rates }\end{array}$ \\
\hline
\end{tabular}

Abbreviations: miRNA, microRNA; GBMs, glioblastomas.

On the other hand, several studies have reported that miR$200 \mathrm{c}$ plays an important role in regulating glioma cell growth and invasion. For example, one study showed that miR-200c overexpression impaired glioma cell proliferation and invasion by targeting moesin. ${ }^{15}$ Another study found that miR$200 \mathrm{c}$ prevented the invasion and migration of glioblastoma by activating EGFR pathways that reversed the epithelialmesenchymal transition in glioblastoma. ${ }^{36}$ Intriguingly, due to the homology in seed sequences, miR-200c and miR-141 share the same target, ZEB1, which is known to inhibit glioma cell growth and migration. ${ }^{37}$ However, recent studies obtained inconsistent results. For example, one study reported that miR-141, acting as a tumor suppressor, inhibited glioma cell proliferation, migration and invasion by targeting TGF- $\beta 2,{ }^{20}$ while another study indicated that miR-141-3p promoted glioblastoma progression and temozolomide resistance by targeting $\mathrm{p} 53 .{ }^{24}$ Similarly, another report suggested that miR429 was a potential tumor-suppressive miRNA and inhibited glioblastoma proliferation by targeting SOX $2,{ }^{38}$ while a contrasting study reported that miR-429 was upregulated in glioma tissues, suggesting that miR-429 contributes to glioma progression. ${ }^{23}$ The exact reason for the discrepancies in these studies is still unclear, but it suggests that members of miR200 family might play context-dependent roles. Hence, more studies are needed to clarify the functional roles of miR-200 family in gliomas.

Long non-coding RNAs (lncRNAs) might also interact with microRNAs in glioma. ${ }^{39}$ One study reported that miR200a was negatively regulated by the IncRNA ATB, which is involved in glioma malignancy. ${ }^{40}$ LncRNA TCF7 can also bind to miR-200c and inhibit miR-200c expression, which can promote glioma cell proliferation, self-renewal and 
migration. ${ }^{41}$ Conversely, increasing data indicate that miRNAs have the capacity to regulate lncRNAs. For example, lncRNA HOTAIR was found to be a downstream target of miR-141, which is involved in glioma cell proliferation, migration and invasion..$^{42}$ One study also demonstrated that miR-429 directly targeted the lncRNA XIST, which promoted glioma tumorigenicity. ${ }^{43}$ Therefore, a better understanding of the relationship between lncRNA and miRNA can help to develop potentially new therapeutic strategies for gliomas.

\section{Effect of miR-200 on chemotherapeutic and radiotherapeutic responses and glioma prognosis}

Given the difficulty in resecting whole glioma tumors, relapse frequently occurs following surgery. Therefore, treatment schemes for gliomas often include chemotherapy and/or radiotherapy after surgery. The first-line glioma drugs are temozolomide and bevacizumab. However, due to resistance to chemotherapeutic drugs and intolerance to radiotherapy, patients with glioma have poor prognoses. Increasing data indicate that the miR-200 family might contribute to some of the drug resistance in glioma treatment.

High levels of the DNA repair enzyme, $\mathrm{O}^{6}$-methylguanine methyltransferase (MGMT), are thought to be the main mechanism by which glioblastoma develops resistance to temozolomide. ${ }^{44,45}$ Interestingly, one study found that overexpression of miR-200a inhibits MGMT activity and promotes temozolomide sensitivity; however, overexpression of MGMT also inhibited miR-200a expression. ${ }^{17}$ The exact mechanism by which MGMT affects miR-200a remains unclear, but some reports speculate that apoptosis is involved. ${ }^{17,46}$ In addition, although several studies have reported that miR-141 functions as a tumor suppressor that represses glioma cell proliferation and invasion, ${ }^{20}$ one study indicated that miR-141-3p promoted temozolomide resistance by inhibiting p53 expression in an orthotopic mouse model of human glioma, and that inhibition of miRNA-141-3p reduced glioma cell growth and prolonged survival rates in glioma-bearing mice. ${ }^{24}$ Radiotherapy is an additional glioma treatment strategy. One study demonstrated that miR-200c increases glioma cell radiosensitivity by activating EGFR-associated signaling. ${ }^{36}$

Apart from chemotherapy and radiotherapy, immunotherapy has recently emerged as an alternative glioma treatment. ${ }^{47-49}$ However, some glioma patients benefit from immunotherapy, but others do not. ${ }^{50}$ For those who do not respond to immunotherapy alone, combinatorial treatment with miRNAs may by prove beneficial. Evidence suggested that the miR-200 family could modulate the tumor immune response. For example, myeloid-derived suppressor cells (MDSCs) can produce reactive oxygen species and suppress tumor immune response and modulate the tumor environment. ${ }^{51}$ Furthermore, it was reported that miR-200c plays a significant role in the regulation of tumor-associated MDSCs. ${ }^{52}$ However, the exact relationship between the miR-200 family and glioma immunotherapy is still largely unknown. Therefore, future detailed studies are needed to improve the efficacy of immunotherapy.

Overall, the current data suggest that the miR-200 family could influence clinical outcomes and glioma prognosis through multiple mechanisms. Indeed, it has been clearly demonstrated that higher miR-200b expression correlates with better outcomes and a significantly higher 5-year survival rate in glioma patients and that reduced miR-200b expression might be associated with poor prognosis. ${ }^{18,22,25,53}$ In contrast, one study reported that high miR-429 expression correlates with poor prognosis in glioma patients, ${ }^{23}$ while other studies indicated that miR-429 functions as either an oncogene or a tumor suppressor. ${ }^{54,55}$ The underlying mechanism for this discrepancy is unknown; therefore, more research is needed to clarify the roles of miR-429 in gliomas.

\section{Interactions among different members of the miR-200 family in gliomas}

It is well known that, similar to other miRNA families, each miRNA in the miR-200 family can regulate the expression of several mRNAs, and each mRNA can also be regulated by several miRNAs, forming a complex regulatory network (Table 3). Importantly, in gliomas, the target genes dysregulated by miR200 are associated with many conserved signaling pathways involved in cell processes such as cell proliferation, apoptosis, invasion and drug resistance. ${ }^{20,24,36,37}$ Because miR-200 can target multiple downstream genes in glioma tissues, miR200 might play both oncogenic and antioncogenic roles. For instance, TGF- $\beta 2$ regulates many cellular processes including proliferation, differentiation, adhesion and migration. ${ }^{56}$ TGF- $\beta 2$ expression is upregulated in glioma, ${ }^{57}$ and TGF- $\beta 2$ has been found to play an important role in glioma initiation and development. ${ }^{58}$ In this context, miR-141 acts as a tumor suppressor by targeting TGF- $\beta 2 .{ }^{20}$ However, the tumor suppressor p53 is also a direct target of miR-141. ${ }^{24}$ Therefore, miR-141 may also function as an oncogenic factor through negatively targeting p53 to promote tumor growth and inhibit cell apoptosis. Future research should focus on the specific biological context of miR-200 in gliomas. 
Table 3 Target genes of the miR-200 family in glioma tissues

\begin{tabular}{lll}
\hline miRNA & miRNA targets (mRNA) & Reference \\
\hline miR-200a & SIM2-s, TGF- $\beta 2$ & 16,40 \\
miR-200b & RAB family, ZEB2, CREBI, CDI33, LDHA, RhoA, ROCKII, PROMI, ERK5 & $10,18,19,3$ I-35 \\
miR-200c & Moesin, VEGF, HIF-I $\alpha$, MMP2, ZEBI & $15,36,37$ \\
miR-14I & ATF5, ZEBI, TGF- $\beta 2$, P53, HOTAIR, SKA2 & $14,20,24,37,42$ \\
miR-429 & BMKI, SOX2 & 21,38 \\
\hline
\end{tabular}

Abbreviation: miRNA, microRNA.

\section{Conclusion}

Numerous studies have shown that members of the miR-200 family, as epigenetic regulatory molecules, can regulate physiological and pathological processes through targeting multiple downstream genes, consequently affecting proliferation and invasion of glioma cells as well as the therapeutic response and prognosis of gliomas. Intriguingly, the contradictory roles of microRNAs, especially miR-141 and miR-429, may differentially impact glioma development and progression. In the future, more detailed studies are needed to delineate the underlying mechanisms by which miRNAs in the miR-200 family affect glioma cells to develop more efficient treatments.

\section{Disclosure}

The authors report no conflicts of interest in this work.

\section{References}

1. Hassan A, Mosley J, Singh S, Zinn PO. A comprehensive review of genomics and noncoding RNA in gliomas. Top Magn Reson Imaging. 2017;26(1):3-14.

2. Goodenberger ML, Jenkins RB. Genetics of adult glioma. Cancer Genet. 2012;205(12):613-621.

3. Louis DN, Perry A, Reifenberger G, et al. The 2016 world health organization classification of tumors of the central nervous system: a summary. Acta Neumpathol. 2016;131(6):803-820.

4. Ostrom QT, Gittleman H, Liao P, et al. CBTRUS statistical report: primary brain and central nervous system tumors diagnosed in the United States in 2007-2011. Neuro Oncol. 2014;16(suppl 4):iv1-iv63.

5. Omuro A, DeAngelis LM. Glioblastoma and other malignant gliomas: a clinical review. JAMA. 2013;310(17):1842-1850.

6. Cordner R, Black KL, Wheeler CJ. Exploitation of adaptive evolution in glioma treatment. CNS Oncol. 2013;2(2):171-179.

7. Agarwal S, Sane R, Oberoi R, Ohlfest JR, Elmquist WF. Delivery of molecularly targeted therapy to malignant glioma, a disease of the whole brain. Expert Rev Mol Med. 2011;13:e17.

8. Stewart LA. Chemotherapy in adult high-grade glioma: a systematic review and meta-analysis of individual patient data from 12 randomised trials. Lancet. 2002;359(9311):1011-1018.

9. Yu X, Li Z. Serum microRNAs as potential noninvasive biomarkers for glioma. Tumour Biol. 2016;37(2):1407-1410.

10. Zhao C, Ma ZG, Mou SL, Yang YX, Zhang YH, Yao WC. Targeting effect of microRNA on CD133 and its impact analysis on proliferation and invasion of glioma cells. Genet Mol Res. Epub 2017 Mar 30;16(1).

11. Barciszewska AM. MicroRNAs as efficient biomarkers in high-grade gliomas. Folia Neuropathol. 2016;54(4):369-374.
12. Banelli B, Forlani A, Allemanni G, Morabito A, Pistillo MP, Romani M. MicroRNA in glioblastoma: an overview. Int J Genomics. 2017;2017:16 (7639084).

13. Muralidhar G, Barbolina M. The miR-200 family: versatile players in epithelial ovarian cancer. Int J Mol Sci. 2015;16(8):16833-16847.

14. Wang M, Hu M, Li Z, Qian D, Wang B, Liu DX. miR-141-3p functions as a tumor suppressor modulating activating transcription factor 5 in glioma. Biochem Biophys Res Commun. 2017;490(4):1260-1267.

15. Qin Y, Chen W, Liu B, et al. MiR-200c inhibits the tumor progression of glioma via targeting moesin. Theranostics. 2017;7(6):1663-1673.

16. Su Y, He Q, Deng L, et al. MiR-200 aim pairs glioma cell growth, migration, and invasion by targeting SIM2-s. Neuroreport. 2014;25(1):12-17.

17. Berthois Y, Delfino C, Metellus P, et al. Differential expression of miR200a$3 \mathrm{p}$ and $\mathrm{miR} 21$ in gradeII-III and grade IV gliomas: evidence that miR200a$3 p$ is regulated by $\mathrm{O}^{6}$-methylguanine methyltransferase and promotes temozolomide responsiveness. Cancer Biol Ther. 2014;15(7):938-950.

18. Liu Q, Tang H, Liu X, et al. miR-200b as a prognostic factor targets multiple members of RAB family in glioma. Med Oncol. 2014;31(3):859.

19. Li J, Yuan J, Yuan X, et al. MicroRNA-200b inhibits the growth and metastasis of glioma cells via targeting ZEB2. Int J Oncol. 2016;48(2):541-550.

20. Peng T, Zhang S, Li W, Fu S, Luan Y, Zuo L. MicroRNA-141 inhibits glioma cells growth and metastasis by targeting TGF- $\beta 2$. Am J Transl Res. 2016;8(8):3513-3521.

21. Chen W, Zhang B, Guo W, et al. miR-429 inhibits glioma invasion through BMK1 suppression. J Neurooncol. 2015;125(1):43-54.

22. Men D, Liang Y, Chen L. Decreased expression of microRNA-200b is an independent unfavorable prognostic factor for glioma patients. Cancer Epidemiol. 2014;38(2):152-156.

23. Sun X, Li Z, Chen Y. The potential prognostic value of microRNA-429 for human gliomas. Ann Clin Lab Sci. 2016;46(1):44-48.

24. Zhou X, Wu W, Zeng A, et al. MicroRNA-141-3p promotes glioma cell growth and temozolomide resistance by directly targeting $\mathrm{p} 53$. Oncotarget. 2017;8(41):71080-71094.

25. Wang B, Li M, Wu Z, et al. Associations between SOX2 and miR-200b expression with the clinicopathological characteristics and prognosis of patients with glioma. Exp Ther Med. 2015;10(1):88-96.

26. Ning X, Shi Z, Liu X, et al. DNMT1 and EZH2 mediated methylation silences the microRNA-200b/a/429 gene and promotes tumor progression. Cancer Lett. 2015;359(2):198-205.

27. Gowrishankar B, Ibragimova I, Zhou Y, et al. MicroRNA expression signatures of stage, grade, and progression in clear cell RCC. Cancer Biol Ther. 2014;15(3):329-341.

28. Wan L, Pantel K, Kang Y. Tumor metastasis: moving new biological insights into the clinic. Nat Med. 2013;19(11):1450-1464.

29. Lun M, Lok E, Gautam S, Wu E, Wong ET. The natural history of extracranial metastasis from glioblastoma multiforme. J Neurooncol. 2011;105(2):261-273.

30. Pasquier B, Pasquier D, N'Golet A, Panh MH, Couderc P. Extraneural metastases of astrocytomas and glioblastomas: clinicopathological study of two cases and review of literature. Cancer. 1980;45(1):112-125.

31. Peng B, Hu S, Jun Q, et al. MicroRNA-200b targets CREB1 and suppresses cell growth in human malignant glioma. Mol Cell Biochem. 2013;379(1-2):51-58. 
32. Peng B, Hu S, Qin M, Luo D, Zhang X, Zhao H. miR-200b suppresses glioma cell invasion by targeting PROM1. Zhonghua Zhong Liu Za Zhi. 2015;37(1):25-28.

33. Wu J, Cui H, Zhu Z, Wang L. MicroRNA-200b-3p suppresses epithelial-mesenchymal transition and inhibits tumor growth of glioma through down-regulation of ERK5. Biochem Biophys Res Commun. 2016;478(3):1158-1164.

34. Hu S, Jiang Q, Luo D, et al. miR-200b is a key regulator of tumor progression and metabolism targeting lactate dehydrogenase $\mathrm{A}$ in human malignant glioma. Oncotarget. 2016;7(30):48423-48431.

35. Ma T, Xue YX. MiRNA-200b regulates RMP7-induced increases in blood-tumor barrier permeability by targeting RhoA and ROCKII. Front Mol Neurosci. 2016;9:9.

36. Koo T, Cho BJ, Kim DH, et al. MicroRNA-200c increases radiosensitivity of human cancer cells with activated EGFR-associated signaling. Oncotarget. 2017;8(39):65457-65468.

37. Guo E, Wang Z, Wang S. MiR-200c and miR-141 inhibit ZEB1 synergistically and suppress glioma cell growth and migration. Eur Rev Med Pharmacol Sci. 2016;20(16):3385-3391.

38. Dong H, Hao X, Cui B, Guo M. MiR-429 suppresses glioblastoma multiforme by targeting SOX2. Cell Biochem Funct. 2017;35(5): 260-268.

39. Fejes-Toth K, Sotirova V, Sachidanandam R, et al. Post-transcriptional processing generates a diversity of $5^{\prime}$-modified long and short RNAs. Nature. 2009;457(7232):1028-1032.

40. Ma CC, Xiong Z, Zhu GN, et al. Long non-coding RNA ATB promotes glioma malignancy by negatively regulating miR-200a. J Exp Clin Cancer Res. 2016;35(1):90.

41. Zhao J, Zhang L, Zheng L, Hong Y, Zhao L. LncRNATCF7 promotes the growth and self-renewal of glioma cells via suppressing the miR200c-EpCAM axis. Biomed Pharmacother. 2017;97:203-208.

42. Bian EB, Ma CC, He XJ, et al. Epigenetic modification of miR-141 regulates SKA2 by an endogenous 'sponge' HOTAIR in glioma. Oncotarget. 2016;7(21):30610-30625.

43. Cheng Z, Li Z, Ma K, et al. Long non-coding RNA XIST promotes glioma tumorigenicity and angiogenesis by acting as a molecular sponge of miR-429. J Cancer. 2017;8(19):4106-4116.

44. van Nifterik KA, van den Berg J, van der Meide WF, et al. Absence of the MGMT protein as well as methylation of the MGMT promoter predict the sensitivity for temozolomide. Br J Cancer. 2010;103(1): $29-35$.
45. Spiegl-Kreinecker S, Pirker C, Filipits $\mathrm{M}$, et al. $\mathrm{O}^{6}$-Methylguanine DNA methyltransferase protein expression in tumor cells predicts outcome of temozolomide therapy in glioblastoma patients. Neuro Oncol. 2010;12(1):28-36.

46. Roos WP, Kaina B. DNA damage-induced cell death: from specific DNA lesions to the DNA damage response and apoptosis. Cancer Lett. 2013;332(2):237-248.

47. Sakai K, Shimodaira S, Maejima S, et al. Dendritic cell-based immunotherapy targeting Wilms' tumor 1 in patients with recurrent malignant glioma. J Neurosurg. 2015;123(4):989-997.

48. Brown CE, Alizadeh D, Starr R, et al. Regression of glioblastoma after chimeric antigen receptor T-cell therapy. $N$ Engl $J$ Med. 2016;375(26):2561-2569.

49. Fenstermaker RA, Ciesielski MJ, Qiu J, et al. Clinical study of a survivin long peptide vaccine (SurVaxM) in patients with recurrent malignant glioma. Cancer Immunol Immunother. 2016;65(11):1339-1352.

50. Ursu R, Carpentier A, Metellus $P$, et al. Intracerebral injection of $\mathrm{CpG}$ oligonucleotide for patients with de novo glioblastoma-A phase II multicentric, randomised study. Eur J Cancer. 2017;73:30-37.

51. Lechner MG, Liebertz DJ, Epstein AL. Characterization of cytokineinduced myeloid-derived suppressor cells from normal human peripheral blood mononuclear cells. J Immunol. 2010;185(4):2273-2284.

52. Mei S, Xin J, Liu Y, et al. MicroRNA-200c promotes suppressive potential of myeloid-derived suppressor cells by modulating PTEN and FOG2 expression. PLoS One. 2015;10(8):e0135867.

53. Zhang JQ, Yao QH, Kuang YQ, et al. Prognostic value of coexistence of abnormal expression of micro-RNA-200b and cyclic adenosine monophosphate-responsive element-binding protein 1 in human astrocytoma. Hum Pathol. 2014;45(10):2154-2161.

54. Wang P, Cao J, Liu S, et al. Upregulated microRNA-429 inhibits the migration of HCC cells by targeting TRAF6 through the NF-KB pathway. Oncol Rep. 2017;37(5):2883-2890.

55. Han Y, Zhao Q, Zhou J, Shi R. miR-429 mediates tumor growth and metastasis in colorectal cancer. Am J Cancer Res. 2017;7(2):218-233.

56. Sethi A, Jain A, Zode GS, et al. Role of TGFbeta/Smad signaling in gremlin induction of human trabecular mesh-work extracellular matrix proteins. Invest Ophthalmol Vis Sci. 2011;52(8):5251-5259.

57. Wotton D. A CREB1-TGFbeta2 self-sustaining loop in glioblastoma. Cancer Discov. 2014;4(10):1123-1125.

58. Kjellman C, Olofsson SP, Hansson O, et al. Expression of TGF-beta isoforms, TGF-beta receptors, and SMAD molecules at different stages of human glioma. Int $J$ Cancer. 2000;89(3):251-258.
Cancer Management and Research

\section{Publish your work in this journal}

Cancer Management and Research is an international, peer-reviewed open access journal focusing on cancer research and the optimal use of preventative and integrated treatment interventions to achieve improved outcomes, enhanced survival and quality of life for the cancer patient. The manuscript management system is completely online and includes

\section{Dovepress}

a very quick and fair peer-review system, which is all easy to use. Visit http://www.dovepress.com/testimonials.php to read real quotes from published authors. 